\title{
Relationship between Light Use Efficiency and Photochemical Reflectance Index using MODIS Data in Japan
}

\author{
Mitsunori ISHIHARA ${ }^{*}$ and Masayuki TAMURA ${ }^{* *}$ \\ * Graduate School of Systems and Information Engineering, University of Tsukuba, Tsukuba, 305-8573 Japan \\ ** Graduate School of Engineering, Kyoto University, Kyoto, 606-8501 Japan
}

\begin{abstract}
Recent research has shown that the photochemical reflectance index (PRI) can be related to LUE with some success. However, these researches did not use satellite data to calculate PRI. In this study, we used not only laboratory and field data, but also the Moderate Resolution Imaging Spectroradiometer (MODIS) data to calculate PRI and investigated the usefulness or effectiveness of PRI from MODIS data. At the leaf level, $\mathrm{PRI}_{\text {MODIS }}$ was linearly related to the original PRI. At the canopy level, the relation between PRI and PRI $\mathrm{MODIS}$ was different depending on the condition of the plant and the correlation between PRI $I_{\text {MODIs }}$ and PAR showed a

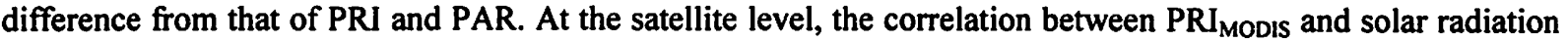
showed a difference from previous research. These results provide a guide for the use of PRI from satellite data as an index of LUE.
\end{abstract}

Key words: LUE, MODIS, NPP, PRI, Solar radiation

\section{Introduction}

Monitoring global net primary production (NPP) is required to understand the global carbon exchange between the atmosphere and the biosphere. The simple light use efficiency (LUE) model is well used for NPP estimation from satellite data (Potter et al., 1993; Ruimy et al. 1994; Running et al., 1999). In this model, NPP is calculated from absorbed photosynthetically active radiation (APAR) and LUE. In the Moderate Resolution Imaging Spectroradiometer (MODIS) NPP algorithm, LUE is calculated using minimum temperature and vapor pressure deficit (VPD) as stress factors (Running et al., 1999). However, this method does not consider reduction in LUE when vegetation receives strong solar radiation. Thus, it is necessary to establish the LUE estimation method in which the effect of strong solar radiation is considered.

On the other hand, it has been shown that the photochemical reflectance index (PRI) derived from narrow band reflectance at $531 \mathrm{~nm}$ (xanthophyll cycle signal) and a reference wavelength has been related to reduction in LUE under strong solar radiation (Gamon et al., 1992; Nichol et al., 2000). The xanthophyll cycle is dissipated light energy as heat under condition of excess light. In this cycle, violaxanthin is converted to zeaxanthin via de-epoxidase reactions. However, previous research only examined relationships between LUE and PRI in a small area with groundbased and helicopter-mounted portable spectroradiometers.

In this study, we have investigated the effectiveness or usefulness of PRI from satellite data as an index of LUE in three levels (leaf, canopy and satellite levels).
We used PRI calculated from MODIS reflectance in band 1 and band 4 .

\section{Methodology}

\subsection{Leaf level measurement}

Liriodendron tulipifera was chosen for the leaf level experiment. The experiment was performed in the laboratory. The leaf spectral reflectance was measured using spectroradiometer (Field Spec Pro FR, Analytical Spectral Devices, U.S.A.). $\Delta \mathrm{F} / \mathrm{Fm}$, an indicator of LUE, was measured by using a pulseamplitude-modulated fluorometer (MINI-PAM, Heinz Walz Gmbh, Germany). The experimental light conditions were changed to $50,100,300,600,900$ and $1200 \mu \mathrm{mol} \mathrm{m}^{-2} \mathrm{~s}^{-1}$ using Photosynthetic Photon Flux Density (PPFD) light meter (LI-250, LI-COR, U.S.A.).

Under the each condition, in order to make a static state, the light was irradiated for 10 minutes before measurements and then the spectral reflectance and $\Delta \mathrm{F} / \mathrm{Fm}$ ' were measured at intervals of 5 minutes during 30 minutes.

\subsection{Canopy level measurement}

Phenology Eyes Network (PEN) data was used for the canopy level measurement (http://www.phenoeye.org/). PEN performs phenology observation with a focus on Asiaflux sites. In these sites, the main instrument is an Automatic-capturing Digital (Fisheye) Camera (ADFC). Other sub instruments are the HemiSpherical Spectro-Radiometer (HSSR) and Sunphotometer (SP). We used HSSR data of the University of Tsukuba's Terrestrial Environmental Research Center from January 1, 2004 to July 31, 2004. 
This site consists of a grass field ( $160 \mathrm{~m}$ in diameter), with a $30 \mathrm{~m}$ high meteorological observation tower with meteorological sensors. Dominant plants are Imperata cylindrica, Solidago altissima and Artemisia princeps. HSSR alternately measures upward and downward radiance at the intervals of 5 minutes. The leaf spectral reflectance was calculated using the average downward radiance in 10 minutes and the upward radiance of the same interval. PAR was calculated using the accumulated downward radiance in the range of 380.32 to $709.26 \mathrm{~nm}$.

\subsection{Satellite level measurement}

The Terra/MODIS 8 day composite data of the Surface-Reflectance Product (MOD 09) in 2001 was used for the satellite level investigation. The areas of mixed forests and croplands of Tsukuba were selected using Terra/MODIS Land Cover products (MOD 12) and Terra/ASTER level $1 \mathrm{~B}$ data. Four pure pixels were chosen from each site and average reflectance was calculated. The amount of solar radiation was obtained from the aerological observatory in Tsukuba. Since this data was values in every hour, the average of eight days was calculated to adjust MODIS reflectance data.

\subsection{Calculation methods}

In this study, we used three indexes investigating the effectiveness or usefulness of PRI from satellite data as an index of LUE.

PRI (Gamon et al., 1992) is formulated as follows:

$$
P R I=\left(R_{570}-R_{531}\right) /\left(R_{570}+R_{531}\right)
$$

where $R_{531}$ is the reflectance at $531 \mathrm{~nm}$ and $R_{570}$ is the reflectance at $570 \mathrm{~nm}$.

PRI $_{\text {MODIS }}$ is formulated as follows:

$$
P R I_{M O D I S}=(B 1-B 4) /(B 1+B 4)
$$

where $B l$ is the reflectance of the MODIS band 1 (620 $-670 \mathrm{~nm}$ ) and $B 4$ is reflectance of the MODIS band 4 $(545-565 \mathrm{~nm})$.

The Normalized Difference Vegetation Index (NDVI) is one of the typical indicators of terrestrial vegetation productivity (Tucker et al., 1985). NDVI was used as index of vegetation condition. $\mathrm{NDVI}_{M O D I S}$ is formulated as follows:

$$
N D V I_{M O D I S}=(B 2-B 1) /(B 2+B 1)
$$

where $B 2$ is the reflectance of the MODIS band 2 ( 841 $-876 \mathrm{~nm})$.

\section{Results and Discussion}

\subsection{Leaf level observation}

The reflectance at each light condition is shown in Fig. 1. The reflectance gradually decreased as PPFD increased. However, the reflectance at $1200 \mu \mathrm{mol} \mathrm{m}^{-}$ ${ }^{2} \mathrm{~s}^{-1}$ increased. In this condition, since the light source was too close to the plant, the plant became too hot.

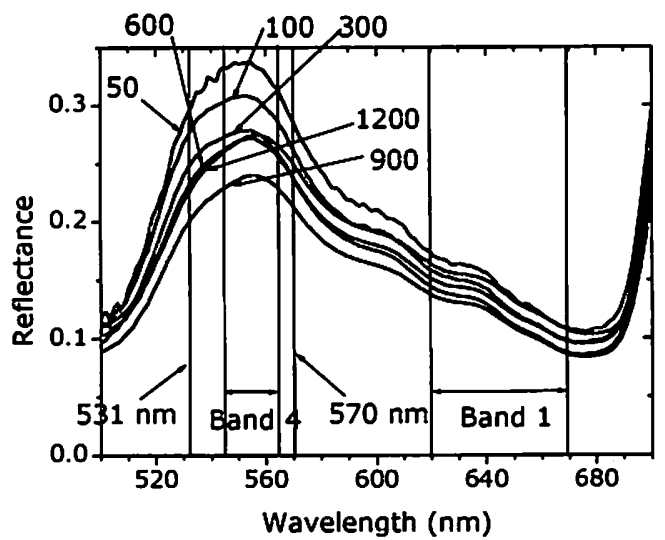

Fig. 1. Spectral reflectance at each light condition. The number in the figure is PPFD.
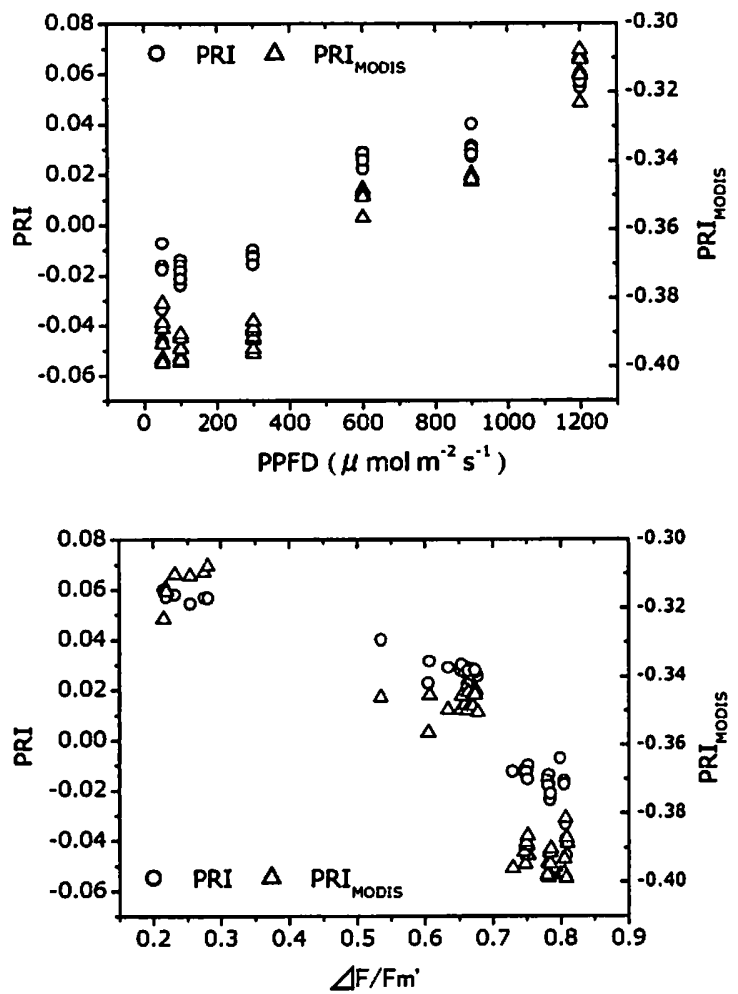

Fig. 2. Scatter plots of PRI and

PRI $_{\text {MODIs versus } P P F D}$ and $\triangle F / F m$ '.

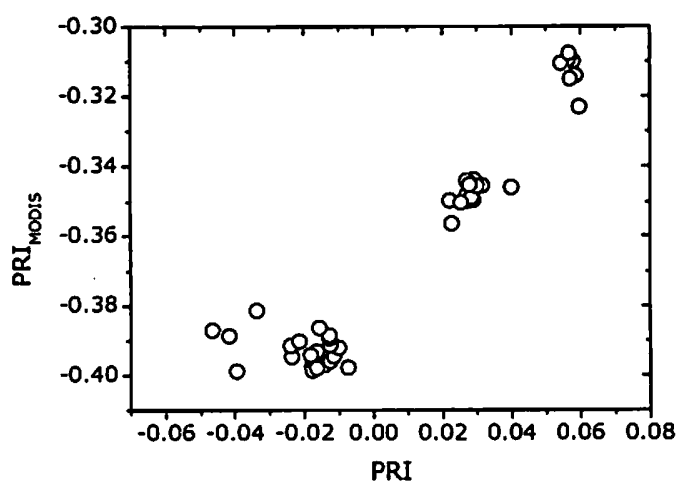

Fig. 3. Scatter plots of PRI and versus $P R I_{\text {MODIS }}$ in the leaf level. 
Thus the plant might undergo other stress apart from excess light.

The relations between PRI, PRI $I_{\text {MODIs }}$ and PPFD, $\Delta$ F/Fm' are shown in Fig. 2. It was observed that PRI and PRI ${ }_{\text {MODS }}$ hardly changed with PPFD of 50 to 300 and 600 to $900 \mu \mathrm{mol} \mathrm{m}^{-2} \mathrm{~s}^{-1}$. When the quantity of light was small, the PRI variation was large. The reason for this is that the quantity of light on the leaf may not actually change. This is a problem of light source and the measurement procedures. In this experiment, the light meter was set by the side of leaf, thus the quantity of light was perhaps different between the light meter and the leaf surface in fact. Thus, it is necessary to improve the experimental method.

There was a positive correlation between PRI and PRI MoDIs (Fig. 3). Therefore, at the leaf level, it is possible to use PRI using the MODIS data instead of the original PRI. However, since there was the variation in the data, it was necessary to increase the measurement.

\subsection{Canopy level observation}

The time series of PRI, PRI $\mathrm{MODIs}_{\text {and }} \mathrm{NDVI}_{\text {MODIs }}$ at 11:00, calculated from PEN data, are shown in Fig. 4. It was observed that there were no plants until March.

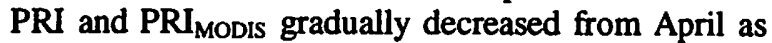
NDVI increased. This result showed that PRI and PRI $_{\text {MODS }}$ were receiving the effect of the seasonal variation of the plants in addition to the strong solar radiation. On the other hand, when the plant canopy reached the saturation state after June, the change of $\mathrm{PRI}_{\text {MODS }}$ was less than PRI. There were two relations between PRI and PRI MODs by the condition of the plants (Fig. 5). PRI was changing more sensitively than PRI

Significant correlations could not be observed between PRI, PRI ${ }_{\text {MoDis }}$ and PAR from April to July (Fig. 6a). On the other hand, there were correlations from June to July (Fig. 6b). However, the correlation between $P R I_{M O D I S}$ and PAR showed a difference from previous research (Tanaka et al., 2003). The main reason for this was that we used MODIS band 1 as a reference band. The reflectance of band 1 was less than $570 \mathrm{~nm}$. Thus, at the canopy level, it is difficult to use PRI ${ }_{\text {MODs }}$ instead of PRI.

\subsection{Satellite level observation}

The time series of $\mathrm{PRI}_{\mathrm{MODIS}}$ and $\mathrm{NDVI}_{\mathrm{MODIS}}$ derived from MODIS data over Tsukuba is shown in Fig. 7. In the croplands, $\mathrm{PRI}_{\mathrm{MODIS}}$ and $\mathrm{NDVI}_{\mathrm{MODIS}}$ changed with almost the same tendency. However, in the mixed forests, PRI greatly changed, though NDVI hardly changed. This result showed that PRI MODIS could express a change of the plant condition that NDVI could not express.

At the satellite level, significant correlations could not be observed between PRI ${ }_{\text {MODIs }}$ and solar radiation over the whole period (Fig. 8). There were correlations in each month of the growth period. However, these correlations were also at different

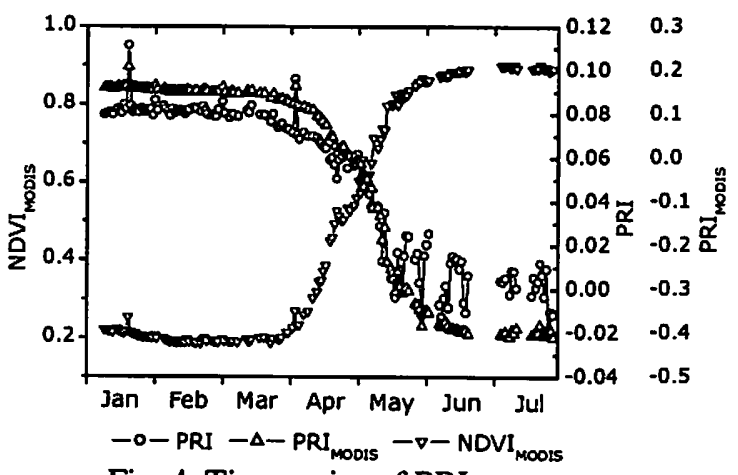

Fig. 4. Time series of PRI,

$\mathrm{PRI}_{\text {MODSS }}$ and NDVI $\mathrm{MODS}_{\text {at }}$ 11:00.

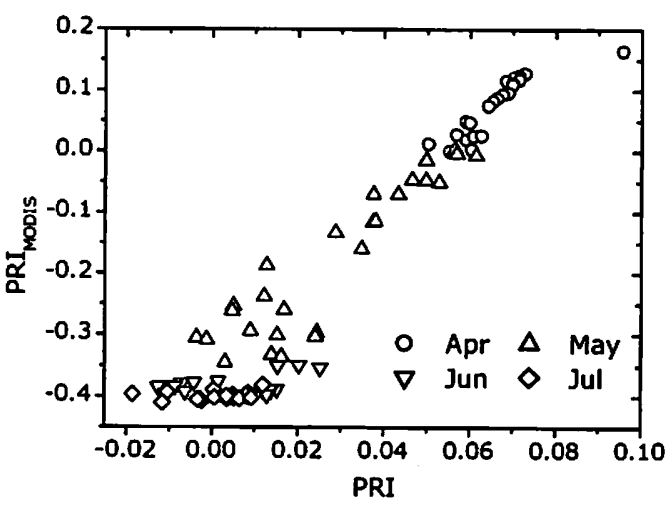

Fig. 5. Scatter plots of PRI and PRI $_{\text {MODis }}$ in the canopy level.
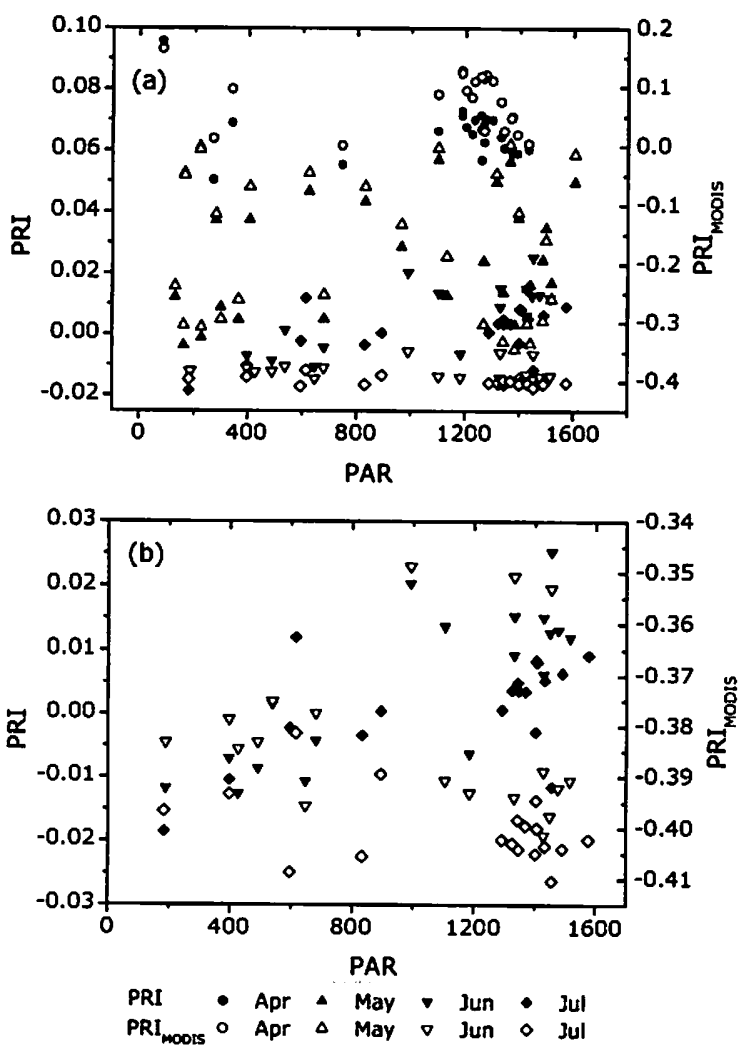

Fig. 6. Scatter plots of PRI and PRI ${ }_{\text {Modis }}$ versus PAR.

(a) From April to July. (b) From June to July. 
from results of previous research. Thus, at the satellite level, it may be difficult to utilize $P R I_{\text {MODIs }}$ for estimation of LUE. It is necessary to consider how $\mathrm{PRI}_{\text {MODIs }}$ is receiving the effect of phenology.

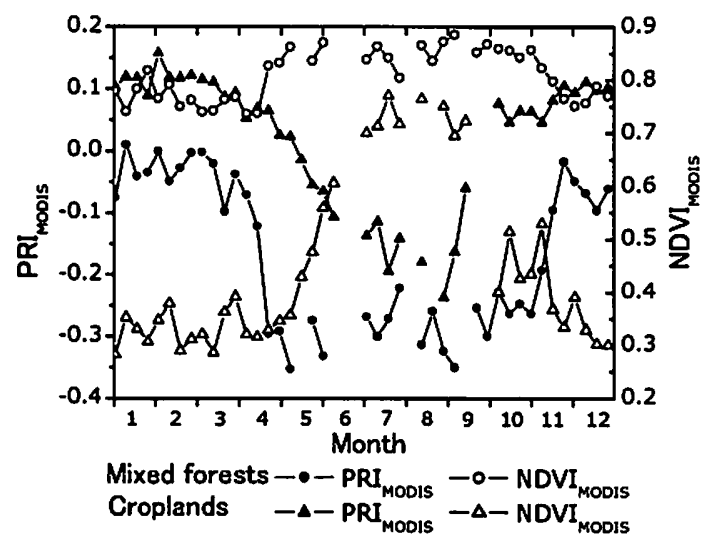

Fig. 7. Time series of $P R I_{\text {MODIs }}$ and $\mathrm{NDVI}_{\text {MODS }}$ in each land cover.
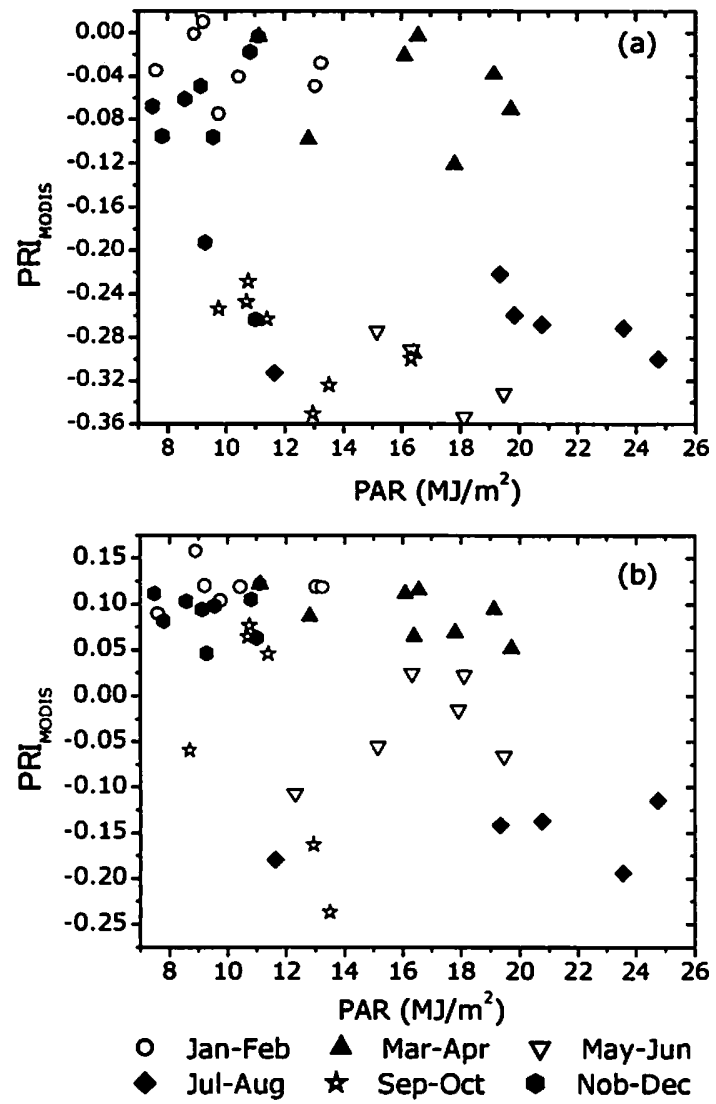

Fig. 8. Scatter plots PRI $_{\text {MODIs }}$ versus solar radiation. (a) Mixed forests. (b) Croplands.

\section{Conclusion}

In this study, we have investigated the effectiveness or usefulness of PRI from satellite data as an index of LUE at three levels. At the leaf level, it was possible to utilize PRI using the MODIS data. However, at the canopy and satellite levels, correlation between $\mathrm{PRI}_{\text {MODIs }}$ and solar radiation showed a different tendency from previous research. The main reason for this was that we used MODIS band 1 as the reference band. It may be difficult to utilize $P R I_{\text {MoDs }}$ as proposed in this study. In the future, we will consider the effect of phenology on $P R I_{\text {MODIs }}$ and investigate the relation between PRI ${ }_{\text {MoDs }}$ and LUE using flux data. We will also think of new PRI ${ }_{\text {MODS }}$ using other MODIS bands.

\section{Acknowledgment}

All MODIS data used in this study were provided by USGS Earth Resource Observation System (EROS) Data Center and HSSR data are provided by the Phenology Eyes Network (PEN) group. We thank Dr. K. Nishida of University of Tsukuba and Dr. S. Tsuchida of Advanced Industrial Science and Technology for providing HSSR data and their invaluable advices.

\section{References}

Gamon J. A., Penuelas J., and Field C. B., 1992: A narrow-waveband spectral index that tracks diurnal changes in photosynthetic efficiency. Remote Sens. Environ., 41, 35-44.

Nichol C. J., Huemmrich K.F., Black T.A., Jarvis P. G., Walthall C. L., Grace J., and Hall F.G., 2000: Remote sensing of photosynthetic-light-use efficiency of boreal forest. Agric. For. Meteorol., 101, 131-142.

Potter C. S., Randerson J. T., Field C. B., Matson P. A., Vitousek P. M., Mooney H. A., and Klooster S. A., 1993: Terrestrial ecosystem production: a process model based on global satellite and surface data. Global Biochem. Cycles, 7, 811-841.

Ruimy A., and Dedieu G., 1994: Methodology for the estimation of terrestrial net primary production from remotely sensed data. J. Geophys. Res., 99 (D3), 5263-5283.

Running S. W., Nemani R., Glassy J. M., and Thornton P. E., 1999: MODIS Daily Photosynthesis (PSN) and Annual Net Primary Production (NPP) Product (MOD17) Algorithm Theoretical Basis Document, http://www.ntsg.umt.edu/modis/ATBD/ATBD_MO D17_v21.pdf.

Tanaka H., Oguma H., and Fujinuma Y., 2003: A seasonal change of PRI and PPFD on the forest canopy. Proceedings of the 35th Conference of RSSJ., 207-208.

Tucker C. J., Vanpraet C. L., Sharman M. J., and Ittersum G. V., 1985: Satellite remote sensing of total herbaceous biomass production in the Senegalese Sahel. Remote Sens. Environ., 17, 233249. 